\title{
The effect of pre-ovulatory anaesthesia on ovulation in laparoscopically inseminated domestic cats
}

\author{
J. G. Howard, M. A. Barone, A. M. Donoghue and D. E. Wildt \\ National Zoological Park, Smithsonian Institution, Washington, DC 20008, USA
}

\begin{abstract}
Summary. Laparoscopic intrauterine artificial insemination (AI) of electroejaculated spermatozoa was used to compare embryo development and conception rates in domestic cats inseminated either before or after ovulation. Females were given a single (100 iu) injection of pregnant mares' serum gonadotrophin (PMSG) followed by either 75 or 100 iu human chorionic gonadotrophin (hCG) $80 \mathrm{~h}$ later. Cats were anaesthetized (injectable ketamine $\mathrm{HCl} /$ acepromazine plus gaseous halothane) $25-50 \mathrm{~h}$ after administration of hCG for laparoscopic assessment of ovarian activity and for transabdominal AI into the proximal aspect of the uterine lumen. At the time of AI, 23 cats were pre-ovulatory (25-33 h after hCG injection) and 30 were post-ovulatory (31-50 h after hCG injection). Pre-ovulatory females produced $10 \cdot 5 \pm 1 \cdot 1$ follicles and no corpora lutea compared with $1.9 \pm 0.5$ follicles and $7.5 \pm 0.9$ corpora lutea for the postovulatory group $(P<0.05)$. Six days later, the ovaries of nine pre-ovulatory and 12 post-ovulatory females were re-examined and the reproductive tracts flushed. On this day, pre-ovulatory cats produced fewer corpora lutea $(2.8 \pm 1.5 ; P<0.05)$ and embryos $(0.4 \pm 0.3 ; P<0.05)$ than post-ovulatory females $(18.9 \pm 3.3$ corpora lutea; $4.6 \pm 1.2$ embryos). Two of the 14 cats $(14.3 \%)$ inseminated before ovulation and not flushed became pregnant compared with 9 of 18 cats $(50.0 \%)$ inseminated after ovulation and up to $41 \mathrm{~h}$ after hCG injection $(P<0.05)$. These results indicate that ovulation in cats is compromised by pre-ovulatory ketamine $\mathrm{HCl}$ /acepromazine/ halothane or laparoscopy or by both and that electroejaculated spermatozoa deposited by laparoscopy in utero, after ovulation, result in a relatively high incidence of pregnancy. Because ovulation usually occurs $25-27 \mathrm{~h}$ after injection of $\mathrm{hCG}$, the lifespan for fertilization of the ovulated ovum appears to be at least $14 \mathrm{~h}$ in vivo in cats.
\end{abstract}

Keywords: ovulation; anaesthesia; artificial insemination; laparoscopy; cat

\section{Introduction}

The domestic cat is important in biomedical research, serving as an animal model for 36 anomalies and metabolic defects homologous to human diseases (Migaki, 1982). The cat is also a valuable model for conservation biology studies because virtually all wild felids are at risk of extinction (Wildt, 1991). Reproductive performance of laboratory cats is poor, especially in populations that have genetic diseases contributing to mortality at an early age or that compromise reproductive behaviour or copulatory ability. Artificial insemination (AI) could be beneficial for (i) individuals that fail to mate because of sexual incompatability or physical/medical handicaps; (ii) increasing the genetic diversity within a population and expanding the gene pool through breeding of selected individuals and (iii) safely distributing semen between different geographical locations without the risk and expense of transporting live animals. The development of $\mathrm{Al}$ techniques in domestic cats may also accelerate the use of artificial breeding in rare, nondomestic felids.

Pregnancies have been achieved in domestic cats after vaginal deposition of semen into anaesthetized queens, but the incidence of pregnancy was only $10.6 \%$ (Platz et al., 1978). This 
low conception rate may be related to improper site of deposition of spermatozoa resulting in compromised sperm transport, or timing of insemination or both with respect to ovulation. We determined that intrauterine insemination using a laparoscopic transabdominal approach was effective for overcoming problems of transport of spermatozoa in common ferrets (Wildt et al., 1989). Vaginal deposition of spermatozoa into ferrets failed to result in pregnancies, whereas depositing spermatozoa in utero resulted in high pregnancy rates $(70 \%)$ using fresh (Wildt et al., 1989) or frozen-thawed (Howard et al., 1991a) semen.

The aims of this present study were to (i) assess the efficacy of laparoscopic intrauterine AI in the domestic cat; and (ii) determine the relationship between onset of ovulation (as potentially influenced by anaesthesia/laparoscopy) and the deposition of spermatozoa into the reproductive tract. Specific objectives were to evaluate the influence of dose of human chorionic gonadotrophin (hCG) on ovarian activity, ovulation and embryo production and compare fertilization, embryo development and pregnancy rate in females inseminated either before or after ovulation. To determine the likelihood that cats were either pre-ovulatory or post-ovulatory, we used the following information. Ovulation in domestic cats occurs only after mating or a comparable artificial stimulus (Wildt \& Seager, 1978; Wildt et al., 1980). Ovarian follicular activity can be stimulated by a single injection of pregnant mares' serum gonadotrophin (PMSG) (Cline et al., 1980). Mature ovarian follicles ovulate approximately $25-27 \mathrm{~h}$ after the administration of hCG (Hamner et al., 1970; Sojka et al., 1970).

\section{Materials and Methods}

\section{Animals and facilities}

Adult cats from random sources (6 males; 54 females) were maintained at the National Institutes of Health (NIH) Animal Center in Poolesville, MD. Males were maintained separately and females were housed in groups of two in stainless-steel cages $(83 \mathrm{~cm}$ high $\times 78 \mathrm{~cm}$ wide $\times 91 \mathrm{~cm}$ deep). Dry, commercial cat food (Purina Cat Chow, Ralston Purina Co., St Louis, MO, USA) and water were available ad libitum.

\section{Induction of follicular development and ovulation}

Females that did not demonstrate oestrous behaviour (Wildt et al., 1978) were given a single (100 iu) intramuscular (i.m.) injection of PMSG (Sigma Chemical Co., St Louis, MO, USA) to induce ovarian follicular development. Eighty hours later, an injection of either 75 ( $n=26$ females) or 100 ( $n=28$ females) iu hCG (Sigma Chemical Co.) was administered i.m. to induce ovulation. Females were anaesthetized for laparoscopy and Al $25-50 \mathrm{~h}$ after hCG injection.

\section{Anaesthesia}

Food and water were withheld from males for $12 \mathrm{~h}$ and females for $24 \mathrm{~h}$ before scheduled anaesthesia. For semen collection, anaesthesia was induced with an i.m. injection of ketamine hydrochloride (HCl) (Vetalar, Parke-Davis, Morris Plains, NJ, USA; $25 \cdot 0 \mathrm{mg} \mathrm{kg}^{-1}$ ). For laparoscopy of females, a surgical plane of anaesthesia was induced with a combination of ketamine $\mathrm{HCl}\left(20.0 \mathrm{mg} \mathrm{kg}^{-1}\right.$; i.m.) and acepromazine (Ayerst Labs, Rouses PT., NY, USA; $0.18 \mathrm{mg} \mathrm{kg}^{-1} ; \mathrm{i} . \mathrm{m}$.) and maintained with halothane gas $(1-2 \%)$ administered via a face mask.

\section{Semen collection and processing}

Semen was recovered by electroejaculation from six proven-breeder males (nine ejaculations per male) and evaluated as described previously (Wildt et al., 1983; Howard et al., 1986, 1990). An aliquot of the ejaculate was examined immediately at $250 \times$ for subjective estimates of the percentage of motile sperm $(0$ to $100 \%)$ and sperm progressive motility on a 0 to 5 scale $(0=$ no movement; $5=$ rapid forward progression $)$. The number of spermatozoa per $\mathrm{ml}$ of ejaculate was determined using a haemocytometer. Sperm morphology was assessed by fixing ejaculate aliquots $(5 \mu \mathrm{l})$ in $1 \%$ glutaraldehyde, followed by phase-contrast microscopic examination of 200 sperm per aliquot at $1000 \times$. Semen samples containing at least $50 \%$ sperm motility and $60 \%$ structurally normal spermatozoa were transferred into a sterile $1.5 \mathrm{ml}$ conical tube (Sarstedt Inc., Princeton, NJ, USA) and slowly diluted with an equal volume of Ham's F10 medium containing 5\% fetal calf serum (Johnston et al., 1991; Irvine Scientific, Irvine, CA, 
USA). Diluted semen was centrifuged ( $300 \mathrm{~g}$ for $10 \mathrm{~min}$ ), the supernatant discarded and the sperm pellet resuspended gently in $210 \mu \mathrm{l}$ of fresh medium. The diluted suspension was assessed for concentration, motility and progressive motility of spermatozoa. Samples were maintained at room temperature $\left(23^{\circ} \mathrm{C}\right)$ and shielded from light until used for AI. A total of $200 \mu \mathrm{l}$ of the sperm suspension was used for $\mathrm{AI}$ of each female ( $100 \mu \mathrm{l}$ per horn). The total number of motile spermatozoa per AI was calculated by multiplying the concentration of spermatozoa by the inseminate volume by sperm $\%$ motility.

\section{Laparoscopic AI}

Each female was subjected to laparoscopy as described earlier (Wildt, 1980). In brief, an intra-abdominal pneumoperitoneum was produced using a Verres needle (inserted lateral to the midline) attached to an automatic insufflator (Richard Wolf Medical Instruments Corp., Rosemont, IL, USA) containing $100 \% \mathrm{CO}_{2}$. A $7 \mathrm{~mm}$ diameter trocar cannula was inserted through a $1 \mathrm{~cm}$ skin incision made $3 \mathrm{~cm}$ cranial to the umbilicus. The trocar was removed and replaced with a rigid, $7 \mathrm{~mm}$ diameter laparoscope (Richard Wolf Medical Instruments Corp.) attached to a light source (Fig. Ia). All aspects of each ovary were examined for pre-ovulatory follicles and post-ovulatory corpora lutea using previously published criteria (Wildt $\&$ Seager, 1978). In brief, pre-ovulatory vesicular follicles $(2-4 \mathrm{~mm}$ in diameter) were clear in appearance, spherical in shape and generally flattened or only slightly raised above the ovarian surface. In contrast, the early developing post-ovulatory corpora lutea (each approximately $4 \mathrm{~mm}$ in diameter) were opaque, dark red and prominently raised $2-3 \mathrm{~mm}$ above the ovarian surface. Cats demonstrating one or more preovulatory follicles and no corpora lutea were classified as pre-ovulatory, whereas, females exhibiting at least one corpus luteum were classified as post-ovulatory regardless of the number of follicles present.

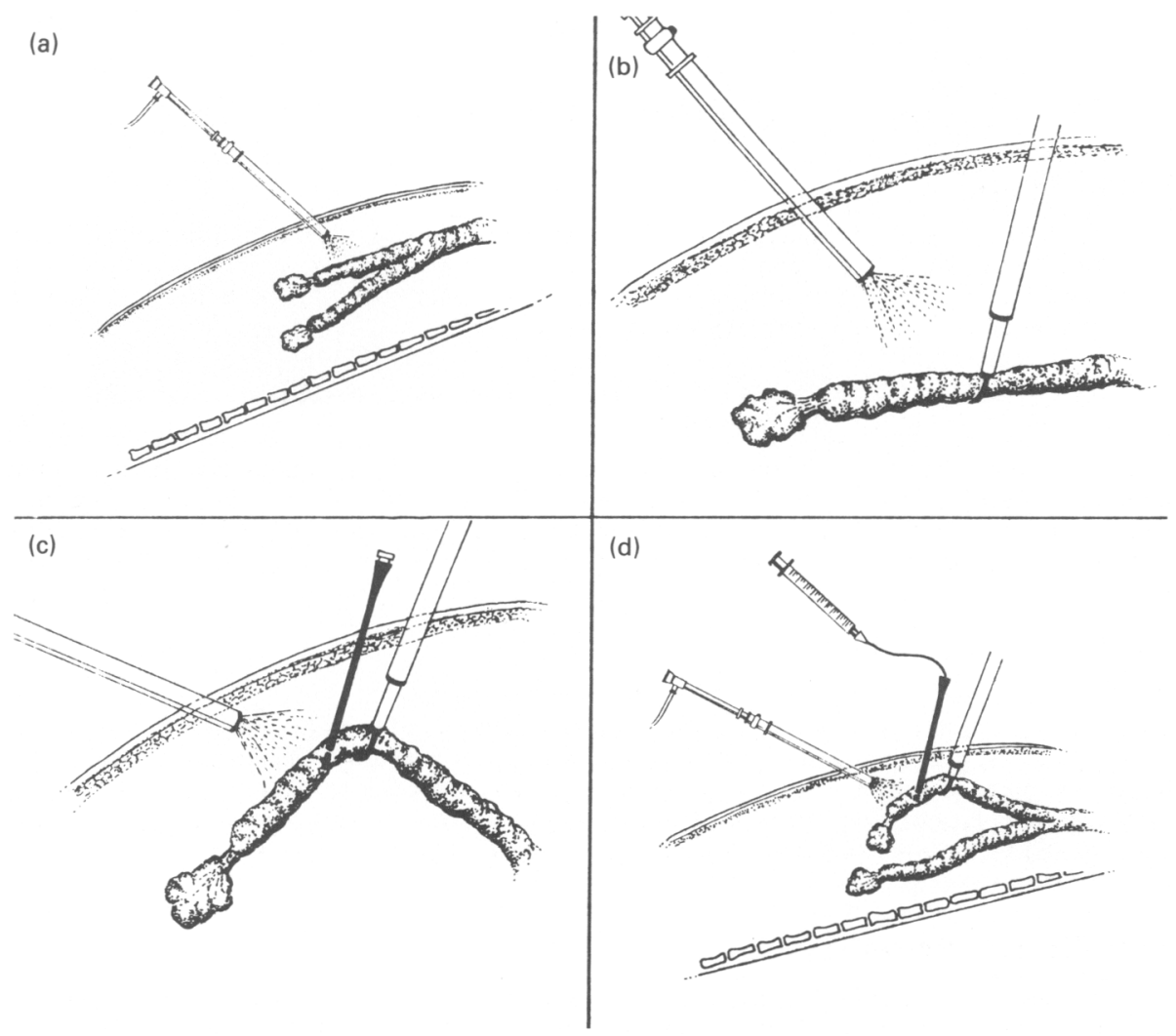

Fig. 1. Laparoscopic intrauterine insemination in domestic cats. (a) The laparoscope was initially used to identify the reproductive tract and (b) accessory forceps were used to grasp the uterine horn. (c) The horn then was elevated and a catheter punctured through the ventral abdominal wall and inserted into the uterine lumen. (d) The stylette was withdrawn from the catheter and tubing containing spermatozoa was guided through the catheter into the uterine lumen for deposition of spermatozoa. 
Intrauterine AI was facilitated by inserting an accessory forceps (Semm's Atraumatic Grasping Forceps, no. 8383.14, Richard Wolf Medical Instruments Corp.) $3 \mathrm{~cm}$ caudal and $4 \mathrm{~cm}$ lateral to the umbilicus to stabilize the uterus (Fig. 1b). Each uterine horn was elevated toward the ventral abdominal wall and cannulated for deposition of spermatozoa in utero using a sterile, feline indwelling catheter (Sovereign, Sherwood Medical, St Louis, MO, USA; 20 gauge, $5 \mathrm{~cm}$ long). The catheter was inserted percutaneously into the proximal third of the uterine lumen under laparoscopic observation (Figs lc, 2). After penetrating the lumen, the stylette was withdrawn slightly within the catheter and the latter advanced. The stylette then was withdrawn completely and replaced with sterile, polyethylene tubing (PE-10, Intramedic, Clay Adams, Parasippany, NJ. USA) attached to a 30 gauge needle and a $1 \mathrm{ml}$ syringe containing $100 \mu \mathrm{l}$ sperm suspension (Fig. 1d). Tubing was advanced through the catheter into the uterine lumen for AI. After depositing a second $100 \mu \mathrm{l}$ sperm sample into the contralateral horn, the catheter, tubing and laparoscopic instruments were removed and the incision sites sutured. The entire anaesthesia/laparoscopy interval (from anaesthesia induction through suturing) was $30-45 \mathrm{~min}$. Additionally, semen was deposited into the uterus of each cat within 30 min to 1 h of ejaculate processing.

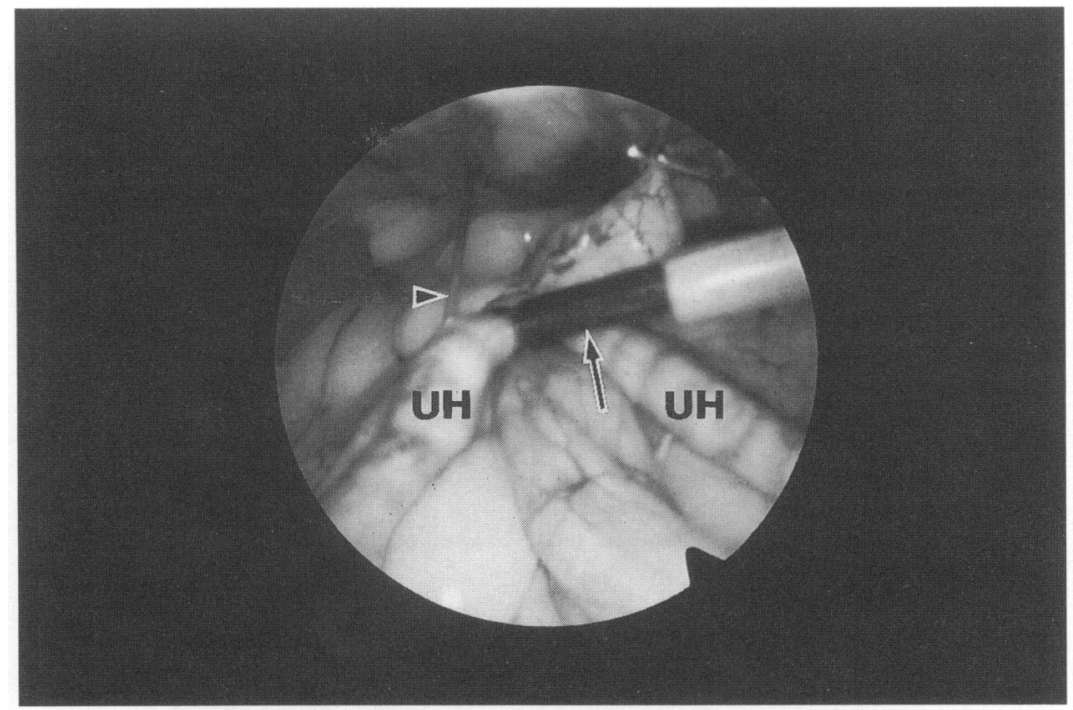

Fig. 2. Laparoscopic insemination of a domestic cat using a grasping forceps (arrow) to stabilize the left uterine horn (UH) and a catheter (arrowhead) inserted percutaneously into the uterine lumen for deposition of spermatozoa.

\section{Embryo collection and evaluation}

Six days after anaesthesia/AI, 21 females classified as either pre-ovulatory $(n=9)$ or post-ovulatory $(n=12)$ were subjected to ovariohysterectomy for re-examination of ovarian activity and embryo collection. Of the 21 cats, 10 (4 pre-ovulatory and 6 post-ovulatory) and 11 ( 5 pre-ovulatory and 6 post-ovulatory) females had received 75 and 100 iu hCG, respectively. In each female, ovaries were assessed for the number of follicles and corpora lutea, and the reproductive tract was flushed from the oviduct to the uterine bifurcation for embryo recovery. The number of unfertilized ova and the number and developmental stage of embryos were determined (Goodrowe et al., 1988a). Percentage fertilization was calculated as the number of embryos divided by the total number of unfertilized ova plus embryos recovered $\times 100$. A quality grade $(Q G)$ of $1,2,3$ or 4 was assigned to embryos of excellent, good, fair or degenerate quality, respectively (Schicwe et al., 1987; Goodrowe et al.. 1988a). Embryos classified as QG 1 or QG 2 contained blastomeres that were spherical (or only slightly asymmetrical) in shape and uniformly dark. QG 3 embryos contained blastomeres that were asymmetrical, pyknotic or pale, and QG 4 embryos contained blastomeres that were degenerate or lysed (Fig. 3).

\section{Pregnancy determination}

The remaining 32 females, which were inseminated and classified as either pre- $(n=14)$ or post- $(n=18)$ ovulatory, were monitored for pregnancy and allowed to complete gestation. Of these females, 16 (6 pre-ovulatory and 10 post-ovulatory) and 16 ( 8 pre-ovulatory and 8 post-ovulatory) had received 75 and 100 iu hCG, respectively. 

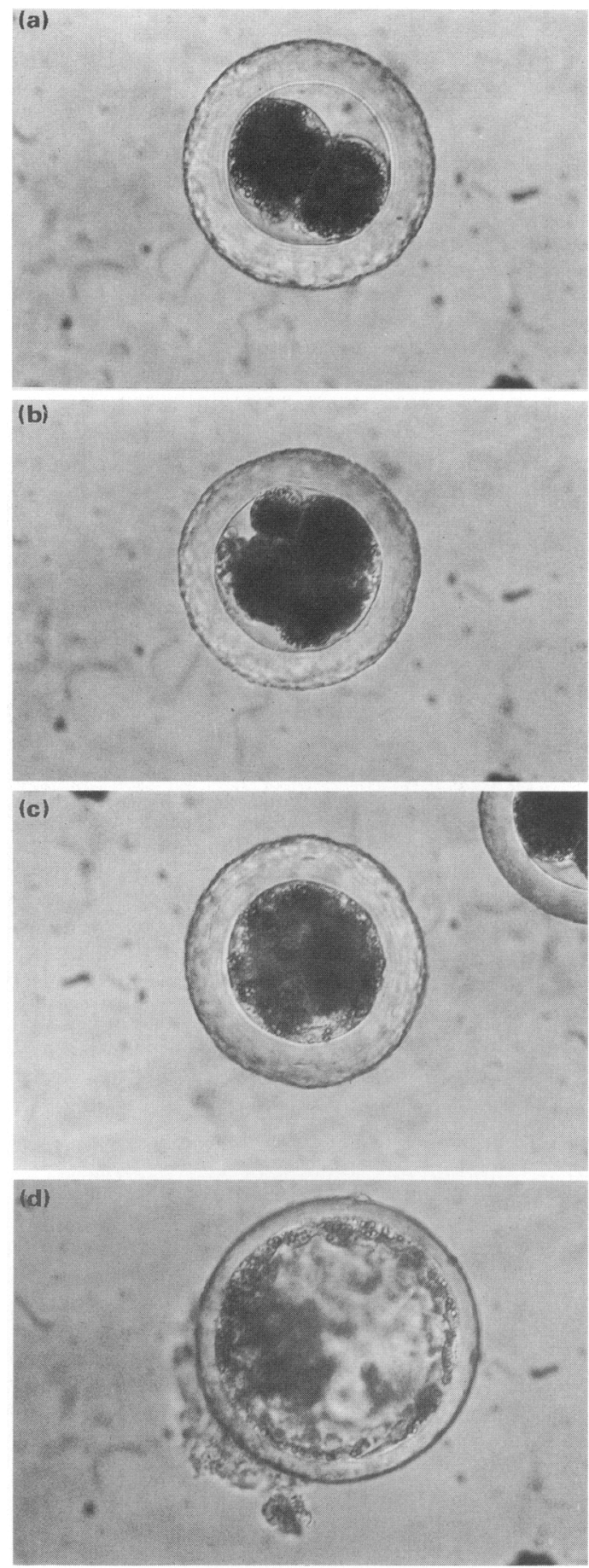

Fig. 3. Embryos of domestic cats recovered 6 days after AI were assigned a quality grade (QG) of 1 (excellent), 2 (good), 3 (fair) or 4 (degenerate). (a) Two-cell embryo, classified as QG 3 owing to the presence of pyknotic blastomeres; (b) eight-cell embryo, classified as QG 3 owing to asymmetrical blastomeres; (c) morula, classified as QG 2; and (d) expanded blastocyst, classified as QG 1. 
Gestation length (defined as the interval from day of AI to day of parturition) and the number of kittens produced per litter were recorded.

\section{Analysis of data}

Values are reported as means \pm standard error of the means (SEM). Differences in the mean number of follicles, corpora lutea, motile spermatozoa inseminated, embryos recovered, gestation interval and litter size between the preovulatory and post-ovulatory groups of cats and the influence of dose of hCG on ovarian activity within each group were analysed using a Student's $t$ test (Snedecor \& Cochran, 1980). Data expressed as a proportion (pregnancy rates between cat groups) were compared by $\chi^{2}$ analysis (Snedecor $\&$ Cochran, 1980).

\section{Results}

The dose of hCG (75 versus $100 \mathrm{iu})$ had no effect $(P>0.05)$ on the number of queens ovulating, or the number of follicles or the number of corpora lutea detected on the day of insemination. Likewise, dose of hCG did not influence $(P>0.05)$ ovarian activity or the number and quality of embryos recovered 6 days later. Pregnancy rates were also similar $(P>0.05)$ between the cats receiving 75 or 100 iu hCG. Data from the two hCG groups were therefore pooled.

A high proportion of females ( 53 of $54 ; 98 \cdot 1 \%$ ) demonstrated follicular activity after PMSG/hCG treatment. At the time of AI, both ovaries of 23 females contained only pre-ovulatory follicles. A retrospective analysis of the times of hormone injection in this pre-ovulatory group revealed that hCG had been given $25-33 \mathrm{~h}$ earlier. At the time of AI, 30 cats had begun ovulation based on the presence of at least one corpus luteum. In this post-ovulatory group, hCG had been administered 31-50 $\mathrm{h}$ earlier. At the time of AI, pre-ovulatory females produced more follicles and fewer corpora lutea $(P<0.05)$ than post-ovulatory females (Table 1$)$. Characteristics of the inseminate were similar $(P>0.05)$ between the two groups (Table 1). Overall, the mean percentage sperm motility, progressive motility, structurally normal spermatozoa and total number of motile spermatozoa inseminated per female were $76 \pm 3,4 \cdot 1 \pm 0 \cdot 1,67 \cdot 2 \pm 5 \cdot 0$ and $6 \cdot 2 \pm 0 \cdot 9 \times 10^{6}$, respectively.

Six days after AI, the ovaries of the pre-ovulatory females still contained more follicles and fewer corpora lutea than those of post-ovulatory females $(P<0.05$; Table 1$)$. At this time, the gross appearance of the follicles did not differ between groups. In the post-ovulatory group, there was a $2 \cdot 5$-fold increase $(P<0.05)$ in the number of follicles and corpora lutea observed 6 days after AI than in those detected on the day of insemination (Table 1).

Cats inseminated after ovulation produced about 11 -fold more $(P<0.05)$ embryos than those inseminated before ovulation (Table 1). Neither the percentage fertilization (overall rate, $67 \cdot 5 \pm 13.0 \%)$ nor the mean number of unfertilized ova per female (overall mean, $0.7 \pm 0.5$ ) differed $(P>0.05)$ between the two groups. A wide range in stage of development was observed in embryos recovered at 6 days after AI (range, two-cell to blastocysts; Table 2; Fig. 3), but this variation was independent of pre-ovulatory versus post-ovulatory AI time (data not shown). Nevertheless, $57 \cdot 1 \%$ of all embryos were morulae or blastocysts, and the mean quality grade of these embryos was higher $(P<0.05)$ than that of any of the earlier stage classifications (Table 2). A large proportion (96.7\%) of the morulae and blastocysts were classified as QG 1 or QG 2, whereas none of the two- to 16-cell embryos were rated as QG 1 , and only $9 \cdot 1 \%$ of these earlier stage embryos were classified as QG 2. Of the blastocysts recovered, $80 \%$ and $20 \%$ were graded as excellent (QG I) and good (QG 2) quality, respectively. Expanded blastocysts were observed in $80 \%$ of the cats producing blastocysts and constituted $30 \%$ of the total blastocysts recovered. Of the morulae recovered, $30 \%, 60 \%$ and $10 \%$ were classified as QG 1, QG 2 and QG 4, respectively.

A 3.5-fold increase in the incidence of pregnancy occurred when cats were inseminated after ovulation compared with those before ovulation (Table 1). In the pre-ovulatory group, both queens that became pregnant were given hCG $26 \mathrm{~h}$ before insemination. In the post-ovulatory group, the mean interval between $\mathrm{hCG}$ administration and $\mathrm{AI}$ was $37.9 \pm 0.9 \mathrm{~h}$ (range, 33-41 h). The number of motile spermatozoa inseminated in all queens that became pregnant $\left(6.6 \pm 1.3 \times 10^{6}\right.$; range 
Table 1. Insemination of domestic cats before or after ovulation and either ovariohysterectomized 6 days after AI or allowed to complete gestation ${ }^{2}$

\begin{tabular}{|c|c|c|}
\hline & $\begin{array}{l}\text { Pre-ovulation } \\
\text { insemination }\end{array}$ & $\begin{array}{l}\text { Post-ovulation } \\
\text { insemination }\end{array}$ \\
\hline \multicolumn{3}{|l|}{ Day of Insemination } \\
\hline Number of females & 23 & 30 \\
\hline Number of follicles per female & $\begin{array}{l}10 \cdot 5 \pm 1 \cdot 1^{b} \\
(5-18)\end{array}$ & $\begin{array}{l}1.9 \pm 0.5^{c} \\
(0-11)\end{array}$ \\
\hline Number of corpora lutea per female & $\begin{array}{r}0 \cdot 0^{\mathrm{b}} \\
(0)\end{array}$ & $\begin{array}{l}7 \cdot 5 \pm 0 \cdot 9^{c} \\
(2-23)\end{array}$ \\
\hline Sperm motility of inseminate $(\%)$ & $75 \pm 4$ & $76 \pm 2$ \\
\hline $\begin{array}{l}\text { Sperm progressive motility of } \\
\text { inseminate (scale } 0-5 \text { ) }\end{array}$ & $4 \cdot 1 \pm 0 \cdot 1$ & $4 \cdot 1 \pm 0 \cdot 1$ \\
\hline $\begin{array}{l}\text { Structurally normal spermatozoa per } \\
\text { inseminate }(\%)\end{array}$ & $70 \cdot 2 \pm 5 \cdot 4$ & $65 \cdot 2 \pm 4 \cdot 8$ \\
\hline $\begin{array}{l}\text { Number of motile sperm inseminated } \\
\text { per female }\left(\times 10^{6}\right)\end{array}$ & $5 \cdot 5 \pm 1 \cdot 3$ & $6 \cdot 8 \pm 0 \cdot 7$ \\
\hline \multicolumn{3}{|l|}{ Ovariohysterectomy -6 days after AI } \\
\hline Number of females & 9 & 12 \\
\hline Number of follicles per female & $\begin{array}{l}8 \cdot 8 \pm 3 \cdot 3^{b} \\
(4-22)\end{array}$ & $\begin{array}{c}5 \cdot 3 \pm 1 \cdot 6^{\mathrm{c}} \\
(0-20)\end{array}$ \\
\hline Number of corpora lutea per female & $\begin{array}{l}2 \cdot 8 \pm 1 \cdot 5^{b} \\
(0-8)\end{array}$ & $\begin{array}{l}18 \cdot 9 \pm 3 \cdot 3^{c} \\
(2-34)\end{array}$ \\
\hline Number of embryos per female & $\begin{array}{l}0 \cdot 4 \pm 0 \cdot 3^{b} \\
(0-2)\end{array}$ & $\begin{array}{l}4 \cdot 6 \pm 1 \cdot 2^{c} \\
(0-11)\end{array}$ \\
\hline \multicolumn{3}{|l|}{ Term pregnancy } \\
\hline Number of females & 14 & 18 \\
\hline Number of pregnant females & $2^{\mathrm{b}}$ & $9^{\mathrm{c}}$ \\
\hline Pregnancy rate & $14.3 \% \%^{\mathrm{b}}$ & $50.0 \%^{\mathrm{c}}$ \\
\hline
\end{tabular}

Table 2. Mean ( \pm SEM) number, developmental stage and quality grade of embryos recovered 6 days after $\mathrm{AI}$ in domestic cats $^{2}$

\begin{tabular}{lcc}
\hline & $\begin{array}{c}\text { Number of embryos } \\
\text { per female }\end{array}$ & $\begin{array}{c}\text { Quality } \\
\text { grade }\end{array}$ \\
\hline Total embryos & $6 \cdot 3 \pm 1 \cdot 2$ & $2 \cdot 3 \pm 0 \cdot 2$ \\
Two- or four-cell embryos & $1 \cdot 2 \pm 0 \cdot 4$ & $3 \cdot 4 \pm 0 \cdot 2^{\mathrm{b}}$ \\
Eight- or 16-cell embryos & $1 \cdot 5 \pm 0 \cdot 4$ & $3 \cdot 4 \pm 0 \cdot 2^{\mathrm{b}}$ \\
Morulae & $1 \cdot 3 \pm 0 \cdot 6$ & $1 \cdot 9 \pm 0 \cdot 3^{\mathrm{c}}$ \\
Blastocysts & $2 \cdot 3 \pm 1 \cdot 2$ & $1 \cdot 2 \pm 0 \cdot 1^{\mathrm{c}}$ \\
\hline
\end{tabular}

${ }^{\mathrm{a}} n=9$ females.

${ }^{\text {b.c }}$ Within columns, means with different superscripts are significantly different $(P<0 \cdot 05)$.

$\left.(2 \cdot 4-19 \cdot 2) \times 10^{6}\right)$ was not different $(P>0.05)$ from that used in the nonpregnant cats (mean $(6 \cdot 3 \pm 0 \cdot 8) \times 10^{6} ;$ range $\left.(1 \cdot 3-12 \cdot 3) \times 10^{6}\right)$. The overall mean duration of gestation and litter size for all cats was $67.6 \pm 0.5$ days (range 66-70) and $1.8 \pm 0.3$ kittens (range 1-4), respectively. These values did not differ $(P>0 \cdot 05)$ between the pre-ovulatory and post-ovulatory groups. 


\section{Discussion}

A single injection of PMSG followed by hCG effectively stimulated ovarian activity in domestic cats to allow successful AI. However, efficiency of AI was based on the time of the anaesthesia required for laparoscopy and deposition of spermatozoa in utero. If ovulation had already commenced by the time of $\mathrm{AI}$, a relatively high pregnancy rate could be expected. However, if anaesthesia/laparoscopy was performed with only pre-ovulatory follicles on the ovaries, then ovulation was usually inhibited and pregnancy rate was low.

The dose of PMSG used here may have been excessive. In the post-ovulatory group, the PMSG treatment produced an expected (normal) number of corpora lutea by the day of laparoscopic AI; but 6 days later, the ovaries were hyperstimulated as evidenced by almost 19 corpora lutea per female. These ancillary corpora lutea probably originate from a secondary wave of follicular activity provoked by the long biological half-life of PMSG that causes continual recruitment of antral follicles (Moor et al., 1984). The adverse effects of this secondary wave are probably more related to altered endocrine profiles rather than to 'extra' oocytes. Goodrowe et al. (1988a) compared embryo recovery and endocrine profiles among mated, naturally oestrous and folliclestimulating hormone pituitary FSH-treated cats and found that the gonadotrophin-treated females produce altered oestradiol and progesterone profiles and fewer embryos of overall lower quality. Tsutsui et al. (1989) confirmed this observation and further demonstrated that pituitary FSHtreated queens occasionally abort during the first 4 weeks of pregnancy owing to decreasing progesterone concentrations indicating inadequate luteal function. In this study, flushing the reproductive tract and examining the embryos for developmental stage and quality demonstrated that these PMSG-treated queens were experiencing considerable ovum and embryo loss. Although about $57 \%$ of the recovered embryos were classified as morulae or blastocysts of good to excellent quality at 6 days after $\mathrm{Al}$, most of the remaining embryos were retarded in development and of poor/degenerative quality. On the basis of our in vitro data (Johnston et al., 1991), cat embryos can be expected to be at the morula- or blastocyst-stage of development 5-6 days after mature oocytes are exposed to spermatozoa. The present study therefore suggests that as many as $43 \%$ of the fertilized oocytes did not survive during the early stages of development. The pregnancy interval in the naturally oestrous/naturally mated cat averages 63 days (Schmidt et al., 1983), which is 3-7 days shorter than the duration of gestation measured in this study. A similar finding has been noted in cats receiving repeated PMSG injections to stimulate oestrus (Colby, 1970). Because the latter cats were not anaesthetized or artificially inseminated, it is possible that these prolonged gestations also resulted from perturbed endocrine profiles caused by suboptimal gonadotrophin therapy. We have studies in progress to determine whether a lower gonadotrophin dose could stimulate oestrus in cats without causing ovarian hyperstimulation.

Our findings of a higher pregnancy rate in domestic cats inseminated after onset of ovulation $(50.0 \%)$ compared with before ovulation $(14.3 \%)$ appears related to an inhibition and/or delay of ovulation caused by the pre-ovulatory administration of anaesthesia. After ketamine $\mathrm{HCl}$ anaesthesia, circulating cortisol is increased significantly for at least $60 \mathrm{~min}$ in male cats (Carter et al., 1984). It is therefore possible that we provoked an acute stress response resulting in high cortisol concentrations which compromised ovulation. Restraint, high temperature or administration of adrenocorticotrophin releasing hormone (ACTH) reduce conception and embryo survival in mice, rats, sheep and pigs (Euker \& Riegle, 1973; Doney et al., 1976; Kittinger et al., 1980; Hemsworth et al., 1986). Administration of ACTH to pigs interferes with ovulation by changing the timing or suppressing the luteinizing hormone $(\mathrm{LH})$ peak (Hennessy \& Williamson, 1983). The endogenous secretion of LH and subsequent ovulation in cats also appear sensitive to anaesthetics. Johnson \& Gay (1981) reported that using ketamine $\mathrm{HCl}$, halothane or pentobarbital in conscious, gonadectomized cats promptly reduces both the frequency and amplitude of pulsatile LH peaks and mean circulating LH concentrations. When anaesthesia was induced in another study with ketamine $\mathrm{HCl} 22 \mathrm{~h}$ after mating, only 7 of 15 females (46\%) ovulated (Shille et al., 1983). 
When anaesthesia was delayed and performed $28-40 \mathrm{~h}$ after mating, 10 of 14 cats $(71 \%)$ ovulated. In retrospect and in the context of the present results, it appears that the use of ketamine $\mathrm{HCl}$ in mated or gonadotrophin-primed, pre-ovulatory cats suppresses ovulation in the late follicular stage of the cycle. This conclusion is also supported by earlier AI studies. Sojka et al. (1970) reported a $50 \%$ conception rate in non-anaesthetized, naturally oestrous queens induced to ovulate with 50 iu hCG. In contrast, Platz et al. (1978) achieved only a $10 \cdot 6 \%$ conception rate in queens anaesthetized with ketamine $\mathrm{HCl}$ using frozen-thawed spermatozoa. Although this relatively low rate of efficiency was originally attributed to low viability of spermatozoa after cyropreservation, it is also likely that ovulation was suppressed by the anaesthetic in some of these queens.

The mechanism by which anaesthesia compromises ovulation after hCG injection is unknown. Since hCG has been demonstrated to compete with $\mathrm{LH}$ for the same receptors in ovarian tissue, the site of dysfunction may be the ovary with specific uncoupling of the LH-receptor complex on the granulosa cell surface, thus reducing cyclic AMP production needed to activate protein kinases and protein phosphorylation events essential for ovulation (Koch et al., 1974). The mechanism by which these anaesthetics specifically influence this sequence remains to be studied.

The laparoscopic intrauterine insemination technique was effective for artificial breeding in domestic cats. Although vaginal deposition of spermatozoa was not assessed in this study, AI trials in other carnivore and livestock species have demonstrated the advantages of depositing spermatozoa directly into the uterus. Vaginal AI with fresh or frozen semen fails to result in pregnancies in the blue fox (Alopex lagopus), despite using specialized equipment for preventing seminal backflow from the vagina (Aamdal et al., 1972). In contrast, intrauterine deposition of spermatozoa via the cervix in the blue and silverfox (Vulpes vulpes) results in pregnancy rates comparable to those obtained after natural mating (Fougner, 1989). Our studies in domestic ferrets have confirmed the ineffectiveness of vaginal AI, whereas laparoscopic insemination in utero consistently results in pregnancy rates of $70 \%$ or greater using fresh or thawed spermatozoa (Wildt $e t$ al., 1989; Howard et al., 1991a). In sheep, abnormal transport of spermatozoa through the cervix has been associated with gonadotrophin stimulation, oestrous synchronization treatments and reduced viability of frozen-thawed spermatozoa (Evans \& Armstrong, 1984; Hawk et al., 1987). However, intrauterine insemination via laparotomy (Trounson \& Moore, 1974) or laparoscopy (Killeen \& Caffery, 1982; Armstrong \& Evans, 1984; Schiewe et al., 1984) has circumvented the problem of poor transport of spermatozoa. The cervix and its secretions have also been shown to play a 'filtering' role in preventing certain types of morphologically abnormal spermatozoa from reaching the site of fertilization (Freundl et al., 1988). If this is the case in felids, then perhaps the cervix and cervical mucus also act as a partial barrier to some normal spermatozoa as well. Because many felid species ejaculate relatively low concentrations of spermatozoa and a relatively high incidence of abnormal forms with compromised sperm function (Wildt et al., 1983; Howard et al., 1984, 1990, 1991b, 1991c; Wildt, 1991), it is understandable that vaginal insemination may be inefficient. Bypassing the cervical barrier undoubtedly places more spermatozoa near the site of fertilization.

Although the minimum number of spermatozoa necessary to achieve a pregnancy in domestic cats is unknown, we showed that conceptions occurred when as few as $2.4 \times 10^{6}$ motile spermatozoa were deposited in utero. Domestic cats produce low volume ejaculates (about $100 \mu \mathrm{l}$ ), and the number of motile spermatozoa per ejaculate ranges from $(17$ to 24$) \times 10^{6}$ (Howard et al., 1990). The ejaculate from a single male can therefore be divided and used to inseminate several females. A similar strategy was effective in domestic ferrets, a species producing approximately $28 \times 10^{6}$ motile sperm per ejaculate (Wildt et al., 1989; Howard et al., 1991a). Ferret pregnancies result after intrauterine AI using as few as $1.4 \times 10^{6}$ motile spermatozoa.

Because pregnancies resulted in cats when AI was conducted as late as $41 \mathrm{~h}$ after hCG injection, and, assuming that ovulation usually occurred 25-27 h after hCG injection (Hamner et al., 1970; Sojka et al., 1970), ova of domestic cats must retain their fertilizing capacity in vivo for at least $14 \mathrm{~h}$ 
after ovulation. We have demonstrated from in vitro studies that unovulated oocytes of cats remain viable within the follicle for extended periods before collection for subsequent in vitro fertilization (Goodrowe et al., 1988b; Donoghue et al., 1992). Adult cats were treated with PMSG followed by hCG 72, 80, 84, 88, 92 and $96 \mathrm{~h}$ later. Follicular oocytes were aspirated laparoscopically $25-29 \mathrm{~h}$ after hCG and co-cultured in vitro with ejaculated spermatozoa. Oocytes in each PMSG-hCG interval were fertilized in vitro. Cat ova are therefore sustained for long periods both within the follicle (before ovulation) and the oviduct (after ovulation).

In summary, AI in anaesthetized, gonadotrophin-treated cats was efficient when freshly ejaculated, washed spermatozoa were deposited laparoscopically, but only after the onset of ovulation. We have used this procedure to help propagate laboratory cat models with lysosomal storage diseases including mucopolysaccharidosis (Howard et al., 1992). There is also no reason why laparoscopic AI could not be used to infuse genetic diversity into genetically stagnant populations or to assist in the captive breeding of rare species. In this context, we have extended the laparoscopic AI technique to the endangered leopard cat (Felis bengalensis), a small ( $2-5 \mathrm{~kg}$ body weight) felid whose natural habitat extends through much of Asia (Howard \& Wildt, 1990). One pregnancy has resulted after PMSG-hCG administration and intrauterine AI performed $38 \mathrm{~h}$ after hCG injection (Howard, 1991a). The leopard cat was post-ovulatory at the time of AI. The laparoscopic AI technique has also been successful in the highly endangered cheetah (Acinonyx jubatus), a species exhibiting extreme lack of genetic variation and a high incidence of teratospermia (approximately 70\% abnormal spermatozoa per ejaculate) (Wildt, 1991; Wildt et al., 1983; Howard et al., 1984, 1991c). A single cheetah cub was produced after a modified PMSG-hCG stimulation regimen and intrauterine insemination in a post-ovulatory female (Howard, 1991b). If this technique is to be extrapolated to other wild felids in which limited gamete information is available, knowing that AI can be performed up to $41 \mathrm{~h}$ after hCG injection provides a relatively wide window of opportunity to ensure successful gamete interaction in vivo.

The authors thank S. Hurlbut and T. Cummings for their technical expertise, Diane Walden $\mathrm{Naab}$ for the schematic diagram of the laparoscopic AI procedure and the staff of the National Institutes of Health Animal Center for assistance and animal care. This research was supported by grants from the National Institutes of Health (RR00045) and US Fish and Wildlife Service (D0114160004).

\section{References}

Aamdal, J., Andersen, K. \& Fougner, J.A. (1972) Insemination with frozen semen in the blue fox. Proceedings of the 7th International Congress on Animal Reproduction and Artificial Insemination 4, 1713-1716.

Armstrong, D.T. \& Evans, G. (1984) Intrauterine insemination enhances fertility of frozen semen in superovulated ewes. Journal of Reproduction and Fertility 71, 89-94.

Carter, K.K., Chakraborty, P.K., Bush, M. \& Wildt, D.E. (1984) Effects of electro-ejaculation and ketamine$\mathrm{HCl}$ on serum cortisol, progesterone and testosterone in the male cat. Journal of Andrology 5, 431-437.

Cline, E.M., Jennings, L.L. \& Sojka, N.J. (1980) Breeding laboratory cats during artificially induced estrus. Laboratory Animal Science 30, 1003-1005.

Colby, E.D. (1970) Induced estrus and timed pregnancies in cats. Laboratory Animal Care 20, 1075-1080.

Doney, J.M., Smith, W.F. \& Gunn, R.G. (1976) Effects of post-mating environmental stress or administration of ACTH on early embryonic loss in sheep. Journal of Agricultural Science 87, 133-136.
Donoghue, A.M., Johnston, L.A., Munson, L., Brown, J.L. \& Wildt, D.E. (1992) Influence of gonadotropin treatment interval on follicular maturation, in vitro fertilization, circulating steroid concentrations and subsequent luteal function in the domestic cat. Biology of Reproduction 46, 972-980.

Euker, J.S. \& Riegle, G.D. (1973) Effects of stress on pregnancy in the rat. Journal of Reproduction and Fertility 34, 343-346.

Evans, G. \& Armstrong, D.T. (1984) Reduction of sperm transport in ewes by super-ovulation treatments. Journal of Reproduction and Fertility $\mathbf{7 0}$, 47-53.

Fougner, J.A. (1989) Artificial insemination in fox breeding. Journal of Reproduction and Fertility, Supplement 39, 317-323.

Freundl, G., Grimm, H.J. \& Hofmann, N. (1988) Selective filtration of abnormal spermatozoa by the cervical mucus. Human Reproduction 3, 277-280.

Goodrowe, K.L., Howard, J.G. \& Wildt, D.E. (1988a) Comparison of embryo recovery, embryo quality, oestradiol- $17 \beta$ and progesterone profiles in domestic 
cats at natural or induced oestrus. Journal of Reproduction and Fertility 82, 553-561.

Goodrowe, K.L., Wall, R.J., O'Brien, S.J., Schmidt, P.M. \& Wildt, D.E. (1988b) Developmental competence of domestic cat follicular oocytes after fertilization in vitro. Biology of Reproduction 39, 355-372.

Hamner, C.E., Jennings, L. \& Sojka, N.J. (1970) Cat (Felis catus) spermatozoa require capacitation. Journal of Reproduction and Fertility 23, 477-480.

Hawk, H.W., Cooper, B.S. \& Conley, H.H. (1987) Inhibition of sperm transport and fertilization in superovulating ewes. Theriogenology 28, 139-153.

Hemsworth, P.H., Barnett, J.L. \& Hansen, C. (1986) The influence of handling by humans on the behaviour, reproduction and corticosteroids of male and female pigs. Applied Animal Behaviour Science 15, 303-314.

Hennessy, D.P. \& Williamson, P. (1983) The effects of stress and of ACTH administration on hormone profiles, oestrus and ovulation in pigs. Theriogenology 20, 1326.

Howard, J.G. (1991a) Successful laparoscopic artificial insemination in the leopard cat. American Association of Zoological Parks and Aquariums Communiqué. June, p. 15.

Howard, J.G. (199lb) First cheetah cub produced by artificial insemination. American Association of Zoological Parks and Aquariums Communiqué. October, p. 13.

Howard, J.G. \& Wildt, D.E. (1990) Ejaculate-hormonal traits in the leopard cat (Felis bengalensis) and sperm function as measured by in vitro penetration of zonafree hamster ova and zona-intact domestic cat oocytes. Molecular Reproduction and Development 26, $163-174$.

Howard, J.G., Bush, M., Hall, L.L. \& Wildt, D.E. (1984) Morphological abnormalities in spermatozoa of 28 species of nondomestic felids. Proceedings of the 10th International Congress on Animal Reproduction and Artificial Insemination 2, 57-59.

Howard, J.G., Bush, M. \& Wildt, D.E. (1986) Semen collection, analysis and cryopreservation in nondomestic mammals. In Current Therapy in Theriogenology, pp. 1047-1053. Ed. D. A. Morrow. W. B. Saunders Co., Philadelphia.

Howard, J.G., Brown, J.L., Bush, M. \& Wildt, D.E. (1990) Teratospermic and normospermic domestic cats: ejaculate traits, pituitary-gonadal hormones and improvement of spermatozoal motility and morphology after swim-up processing. Journal of Andrology 11, 204-215.

Howard, J.G., Bush, M., Morton, C., Morton, F., Wentzel, K. \& Wildt, D.E. (1991a) Comparative semen cryopreservation in ferrets (Mustela putorius furo) and pregnancies after laparoscopic intrauterine insemination with frozen-thawed spermatozoa. Journal of Reproduction and Fertility 92, 109-118.

Howard, J.G., Bush, M. \& Wildt, D.E. (1991b) Teratospermia in domestic cats compromises penetration of zona-free hamster ova and cat zonae pellucidae. Journal of Andrology 12, 36-45.

Howard, J.G., Barone, M.A., Bush, M. \& Wildt, D.E. (1991c) A heterologous salt-stored zonae pellucidae assay for assessing sperm capacitation and the impact of teratospermia in the cheetah (Acinonyx jubatus). Journal of Andrology (Supplement 1) Abstract 101.
Howard, J., Haskins, M., Patterson, D., McAloose, D., Baker, H., Just, C., Gasper, P. \& Thrall, M. (1992) Assisted reproduction in feline animal models of human disease. Proceedings of the 43rd Annual Meeting of the American Association for Laboratory Animal Science Abstract PS52.

Johnson, L.M. \& Gay, V.L. (1981) Luteinizing hormone in the cat. I. Tonic secretion. Endocrinology 109, 240-246.

Johnston, L.A., Donoghue, A.M., O'Brien, S.J. \& Wildt, D.E. (1991) Culture medium and protein supplementation influence in vitro fertilization and embryo development in the domestic cat. Journal of Experimental Zoology 257, 350-359.

Killeen, I.D. \& Caffery, G.J. (1982) Uterine insemination of ewes with the aid of a laparoscope. Australian Veterinary Journal 59, 95.

Koch, Y., Zor, U., Chobsieng, P., Lamprecht, S.A., Pomerantz, S. \& Lindner, H.R. (1974) Binding of luteinizing hormone and human chorionic gonadotrophin to ovarian cells and activation of adenylate cyclase. Journal of Endocrinology 61, 179-191.

Kittinger, J.W., Guttierrez-Cernosek, R.M., Cernosek, S.F., Jr. \& Pasley, J.N. (1980) Effects of adrenocorticotrophin on pregnancy and prolactin in mice. Endocrinology 107, 616-621.

Migaki, G. (1982) Compendium of inherited metabolic diseases in animals. In Animal Models of Inherited Metabolic Diseases, pp. 473-501. Eds G. Migaki, R. J. Desnick \& D. F. Patterson. Alan R. Liss, Inc., New York.

Moor, R.M., Kruip, Th. A.M. \& Green, D. (1984) Intraovarian control of folliculogenesis: limits to superovulation? Theriogenology 21, 103-116.

Platz, C.C., Wildt, D.E. \& Seager, S.W.J. (1978) Pregnancy in the domestic cat after artificial insemination with previously frozen spermatozoa. Journal of Reproduction and Fertility 52, 279-282.

Schiewe, M.C., Bush, M., Stuart, L.S. \& Wildt, D.E. (1984) Laparoscopic embryo transfer in domestic sheep: a preliminary study. Theriogenology 22, 675-682.

Schiewe, M.C., Schmidt, P.M. \& Wildt, D.E. (1987) A comparative study of mouse embryo freezepreservation including examination of a thermoelectric freezing device. Cryobiology 24, $238-246$.

Schmidt, P.M., Chakraborty, P.K. \& Wildt, D.E. (1983) Ovarian activity, circulating hormones and sexual behavior in the cat. II. Relationships during pregnancy, parturition, lactation and the postpartum estrus. Biology of Reproduction 28, 657-671.

Shille, V.M., Munro, C., Farmer, S.W., Papkoff, H. \& Stabenfeldt, G.H. (1983) Ovarian and endocrine responses in the cat after coitus. Journal of Reproduction and Fertility 68, 29-39.

Snedecor, G.W. \& Cochran, W.G. (1980) Statistical Methods. Iowa State University Press, Ames, IA.

Sojka, N.J., Jennings, L.L. \& Hamner, C.E. (1970) Artificial insemination in the cat (Felis catus). Laboratory Animal Care 20, 198-204.

Trounson, A.O. \& Moore, N.W. (1974) Fertilization in the ewe following multiple ovulation and uterine insemination. Australian Journal of Biological Sciences 27, 301-304.

Tsutsui, T., Sakai, Y., Matsui, Y., Sato, M., Yamane, I., Murao, I. \& Stabenfeldt, G.H. (1989) Induced ovulation in cats using porcine pituitary gland preparation 
during the non-breeding season. Japanese Journal of Veterinary Science 51, 677-683.

Wildt, D.E. (1980) Laparoscopy in the dog and cat. In Animal Laparoscopy, pp. 31-72. Eds R. M. Harrison \& D. E. Wildt. Williams and Wilkins, Baltimore.

Wildt, D.E. (1991) Fertilization in cats. In $A$ Comparative Overview of Mammalian Fertilization, pp. 299-328. Eds B. S. Dunbar \& M. O'Rand. Plenum Publishing Corporation, New York.

Wildt, D.E. \& Seager, S.W.J. (1978) Ovarian response in the estrual cat receiving varying dosages of hCG. Hormone Research 9, 144-150.

Wildt, D.E., Guthrie, S.C. \& Seager, S.W.J. (1978) Ovarian and behavioral cyclicity of the laboratory maintained cat. Hormones and Behaviour 10, 251-257.

Wildt, D.E., Seager, S.W.J. \& Chakraborty, P.K. (1980) Effect of copulatory stimuli on incidence of ovulation and on serum luteinizing hormone in the cat. Endocrinology 107, 1212-1217.

Wildt, D.E., Bush, M., Howard, J.G., O'Brien, S.J., Meltzer, D., van Dyk, A., Ebedes, H. \& Brand, D.J. (1983) Unique seminal quality in the South African cheetah and a comparative evaluation in the domestic cat. Biology of Reproduction 29, 1019-1025.

Wildt, D.E., Bush, M., Morton, C., Morton, F. \& Howard, J.G. (1989) Semen characteristics and testosterone profiles in ferrets kept in a long-day photoperiod, and the influence of hCG timing and sperm dilution medium on pregnancy rate after laparoscopic insemination. Journal of Reproduction and Fertility 86, 349-358.

Received 29 July 1991 